\title{
Solid Waste Management: Efficient Approach towards Sustainable Development in Nigeria
}

\author{
*Nwaokobia, K. ${ }^{1}$, Ogboru R.O. ${ }^{2}$, and Okolie P.L. ${ }^{3}$
}

${ }^{1}$ Department of Agricultural and Bio-Environmental Engineering Technology: Federal Polytechnic, Auchi. Edo State Nigeria.

${ }^{2}$ Research coordinating unit: Forestry Research Institute of Nigeria, p.m.b 5054, Jericho Hills, Ibadan, Oyo State.

3Department of Chemistry: Delta State University, Abraka, p.m.b, 1, Abraka.

\section{ARTICLE INFO}

Article No.: 090117118

Type: Review

DOI: 10.15580/GJEMPS.2018.2.090117118

Submitted: 01/09/2017

Accepted: 09/09/2017

Published: 28/02/2018

${ }^{\star}$ Corresponding Author

Nwaokobia K.

E-mail: nwaokobia.kingsley@

yahoo. com

Phone: 08066755184

Keywords:

Waste, management, environment, development
Solid waste management issues are increasing in the developing world like Nigeria due to increase in population every year. Open dumping and irregular collections of solid waste are creating serious environmental threats in towns. In Nigeria, poor solid waste management practices, lack of funds and the irresponsible behavior of dwellers are reflecting the worst scenario in the country. The major solid waste management issues in the towns of a country like Nigeria are due to rapid urbanization, industrialization, insufficient funds and poor management. Open dumps of municipal solid waste are causing serious negative environmental impacts in Nigeria. Research findings are clearly indicating that due to rapid growth in population, increments in solid waste generation rate, poor management, non-implementation of solid waste legislation and lack of funding are responsible for the solid waste management crises in Nigeria. The faulty solid waste management system is creating negative environmental impacts like land and water pollution, infectious diseases, blockage of open drainages and small canals, and loss of biodiversity in Nigeria. 


\section{INTRODUCTION}

Solid Waste Management remains one of the most daunting Environmental Sanitation challenges facing the country today and it has continually remained at its lowest ebb despite huge investments in the sector (Adegoke 1989). Currently, as a result of industrialization and rapid population growth in many cities and towns, wastes are generated faster than they are collected, transported and disposed. The National Environmental Sanitation Policy sets out to achieve a clean and healthy environment for all Nigerians. In tackling the underlying problems of solid waste management, this Policy Guidelines has recommended effective, efficient and sustainable waste management strategies. Such strategies include, waste minimization at source through re-use, recycle and energy recovery before final disposal. Due emphasis has also been given to the use of locally available, appropriate and easily affordable technologies. The criteria for standardization of the technologies have also been put in place. Furthermore, since the type and volume of waste generated vary with location and season of the year, the preferred waste management options also vary from place to place and season to season (Okecha 2000). Thus, the methods of solid waste management have been hinged on the diverse socio-cultural, religious and topographical considerations that exist in the country.

The growth of human population coupled with increased economic activities in towns and cities result in high rate of solid waste generation. A fundamental attribute of solid waste is that it is inevitable as almost every human activity involves the generation of waste in solid, liquid and gaseous forms. Social dynamics such as modernization and economic development influence waste generation (Singh 1998). This calls for careful planning and adequate resource allocation to forestall a mismatch between the rates of waste generation, rate of collection and disposal.

The management of solid waste is far from being satisfactory in Nigeria. Many parts of our cities and towns do not benefit from any organized waste management service and therefore wastes are unattended to, buried, burnt or disposed haphazardly. In areas where the authorities do the collection, it is often irregular and sporadic. Recycling of waste is negligible while the methods used for collection, transportation and final disposal are very unsatisfactory (Uwaegbulam 2004). Waste when left unattended to for a long time constitutes serious health hazard, causes offensive odour, pollutes underground water sources and decreases environmental aesthetics and quality (FEPA 1998).

Effective and efficient Solid Waste Management is based on a hierarchy of management options: the reduction of waste, its reuse wherever possible, recycling, composting and energy recovery, and final disposal. However, there will always be certain wastes for which incineration is the most reasonable environmental and economic option. The Government policy shall seek to choose the best options for waste management that will minimize the risk of environmental pollution and harm to human health.

The aim of this paper is to develop Policy Guidelines for efficient and sustainable Solid Waste Management in Nigeria, promote a healthy environment by ensuring sanitary Solid Waste Management, minimize waste generation and promote sorting at source, reuse, recycling and energy recovery, ensure safe and nuisance-free disposal of (urban and rural) domestic, medical, and industrial wastes in order to adequately protect public health during and after collection, transportation, treatment and final disposal, promote effective Stakeholders participation in Solid Waste Management, generate employment opportunities, improve the standard of living and thus reduce poverty, optimize labour and equipment in waste management to enhance increased productivity, build an institutional framework capable of ensuring an efficient waste management system, evolve and maintain an indigenous waste management system based on the physical and socio-cultural characteristics of communities, maintain adequate and regular waste management services at affordable cost and improve and safeguard public health and welfare through efficient sanitary Solid Waste Management methods that will be economical, sustainable and guarantee sound environmental quality (Njoku 2006.).

\section{Types of Solid Waste}

Solid waste can be classified into four different types depending on their source, which include:
A) Household waste, generally classified as municipal waste,
b) Industrial waste, as hazardous waste, and
c) Biomedical waste or hospital waste, as infectious waste,
d) Electronic waste (e-waste).

Agunwamba (1998) observed that the number of electronic devices used per capita at the global scale is growing at a rate of about $4 \%$ and will continue to increase as it is becoming the fastest waste stream worldwide.

\section{Importance of a sound solid waste management program}

In an attempt to accelerate the pace of its industrial development, an economically developing nation may fail to pay adequate attention to solid waste management. Such a failure incurs a severe penalty at a later time in the form of resources needlessly lost and a staggering adverse impact on the environment and on public health and safety. The penalty is neither avoided nor lessened by a resolve to do something about the 
waste at a later time, when the country may be in a better position to take appropriate measures.

\section{Environmental and Health Impacts}

The organic fraction of SWM is an important component, not only because it constitutes a sizable fraction of the solid waste stream in a developing country, but also because of its potentially adverse impact upon public health and environmental quality. A major adverse impact is its attraction of rodents and vector insects for which it provides food and shelter. Its impact on environmental quality takes the form of foul odours and unsightliness. These impacts are not confined merely to the disposal site. On the contrary, they pervade the area surrounding the site and wherever the wastes are generated, spread, or accumulated.

Unless an organic waste is appropriately managed, its adverse impact will continue until it has fully decomposed or otherwise stabilized. Uncontrolled or poorly managed intermediate decomposition products can contaminate air, water, and soil resources.

\section{Epidemiological studies}

Studies have shown that a high percentage of workers who handle refuse, and of individuals who live near or on disposal sites, are infected with gastrointestinal parasites, worms, and related organisms. Contamination of this kind is likely at all points where waste is handled.

\section{Framework for management of solid waste}

Integrated Solid Waste Management (ISWM) is a comprehensive waste prevention, recycling, composting, and disposal program. An effective ISWM system considers how to prevent, recycle, and manage solid waste in ways that most effectively protect human health and the environment. ISWM involves evaluating local needs and conditions, and then selecting and combining the most appropriate waste management activities for those conditions FRN (Federal Republic of Nigeria) 1991. The major ISWM activities are waste prevention, recycling and composting, and combustion and disposal in properly designed, constructed, and managed landfills. Each of these activities requires careful planning, financing, collection, and transport, all of which are discussed below:

Waste Prevention: Waste prevention, also called "source reduction", seeks to prevent waste from being generated. Waste prevention strategies include using less packaging, designing products to last longer, and reusing products and materials. Waste prevention helps reduce handling, treatment, and disposal costs and ultimately reduces the generation of methane.
Recycling and Composting: Recycling is a process that involves collecting, reprocessing, and/or recovering certain waste materials (e.g., glass, metal, plastics, paper) to make new materials or products. Some recycled organic materials are rich in nutrients and can be used to improve soils. The conversion of waste materials soil additive is called composting. Recycling and composting generate many environmental and economic benefits. For example, they create jobs and income, supply valuable raw materials to industry, produce soil-enhancing compost, and reduce greenhouse gas emissions and the number of landfills and combustion facilities.

Disposal (landfilling and combustion): These activities are used to manage waste that cannot be prevented or recycled. One way to dispose of waste is to place it in properly designed, constructed, and managed landfills, where it is safely contained. Another way to handle this waste is through combustion. Combustion is the controlled burning of waste, which helps reduce its volume. If the technology is available, properly designed, constructed, and managed landfills can be used to generate energy by recovering methane. Similarly, combustion facilities produce steam and water as a byproduct that can be used to generate energy.

\section{Developing a Plan for Integrated Solid Waste Management}

Planning is the first step in designing or improving a waste management system. Waste management planners should, for example, take into consideration institutional, social, financial, economic, technical, and environmental factors. These factors vary from place to place. Based on these factors, each community has the challenge of selecting the combination of waste management activities that best suits its needs. Because integrated solid waste management involves both shortand long-term choices, it is critical to set achievable goals. While developing your ISWM plan, you should identify goals or objectives (e.g., protect human health, protect water supplies, eliminate open dumping, increase recycling or composting). The ISWM plan will help guide you through the implementation process. Do not neglect to ask for the community's input in developing your plan, so as to ensure an informed public and to increase public acceptance. Government plays an important role in developing and enforcing waste management standards, providing funding, and day-today management.

\section{Institutional roles for efficient and effective waste management}

\section{The Federal Government shall:}

i. Develop, periodically review and update the Policy Guidelines on Solid Waste Management. 
ii. Develop and circulate set standards for equipment procurement and maintenance in Solid Waste Management.

iii. Develop and circulate set standards on private sector participation in Solid Waste Management services.

iv.Prepare a Solid Waste Master Plan as a national blue print for effective Solid Waste Management and ensure its implementation at the appropriate levels of Government.

v. Enact appropriate legislation that will foster successful implementation of the Policy Guidelines and Master Plan.

vi.Source for funds for programme development, specialized studies and capacity building on Solid Waste Management.

vii. Provide technical assistance to States and LGAs in Solid Waste Management.

viii. Initiate relevant programmes for improved Solid Waste Management practises.

ix. Establish a national data bank on Solid Waste Management for planning and development.

$x$. Provide environmental education and awareness on sound Solid Waste Management.

xi. Collaborate with relevant Stakeholders and ESAs on Solid Waste Management.

xii. Register Solid Waste Management facilities that require EIA certification.

\section{The State Government shall:}

- Support and ensure the implementation of the Policy Guidelines on Solid Waste Management.

- Facilitate the implementation of the National Solid Waste Master Plan.

- Enact relevant State Legislation.

- Provide technical support to the LGAs through training and manpower development programs for capacity building and institutional strengthening.

- Support the provision of logistics including financial instruments to facilitate private sector participation in Solid Waste Management.
- Conduct public education and enlightenment on sound Solid Waste Management.

- Conduct research into local options for Solid Waste Management to guide LGAs.

- Establish data bank on Solid Waste Management.

- Provide land for siting waste management facilities.

\section{The Local Government shall:}

- Implement the Policy Guidelines on Solid Waste Management as a statutory obligation.

- Implement the National Solid Waste Master Plan.

- Enact appropriate legislative instruments and establish necessary sanctions and enforcement mechanisms for efficient service delivery.

- Enlist the services of the private sector and other Stakeholders in Solid Waste Management.

- Register and license all operators of waste management facilities and services.

- Make adequate annual budgetary provisions for Solid Waste Management.

- Recruit, train and retrain staff for efficient service delivery.

- Establish a consultative forum with members of the public to build consensus on appropriate strategies for waste management.

- Develop IEC materials on solid waste handling techniques at household level.

- Promote private sector participation in the delivery of waste management options.

\section{The Private Sector shall:}

- Comply with the provisions of the National Policy Guidelines and Master Plan on Solid Waste Management.

- Participate in Solid Waste Management on cost recovery basis. 
- Undertake waste recycling activities in an environmentally sound manner.

- Engage in partnership with Local Governments for better service delivery.

- Undertake research, specialized studies and product development in Solid Waste Management.

- Promote public enlightenment campaigns.

\section{Civil Society Organizations shall:}

- Undertake grassroots mobilization to support appropriate waste management options.

- Promote the adoption of waste separation and resource recovery at household level.

- Promote public enlightenment campaigns on appropriate strategies for waste storage, collection and disposal.

\section{The Public shall:}

- Adopt environment friendly habits and practices.

- Comply with existing Legislation on Solid Waste Management.

- Comply with the provisions of the Policy Guidelines

- Cooperate with other Stakeholders to ensure sustainable Solid Waste Management systems.

- Patronize recycled goods and biodegradable packages.

- Undertake sorting of recyclable components at source and dispose residue at designated sites.

- Segregate hazardous wastes and ensure hygienic and safe disposal.

- Maintain sanitary dustbins in homes

- Adopt the technology of converting local waste into energy generation including biogas.

- Adopt the use of compost as soil conditioner.
- Pay for Solid Waste Management services to ensure its sustainability.

\section{Effective solid waste collection and management service delivery at Local Government Level}

The strategies adopted for waste management at the Local Government level shall relate to the culture, land use types, economic base, climatic conditions, level of urbanization and the existing institutional arrangement. However, the following guidelines are provided as a broad statement to make for strategic interventions in Solid Waste Management in Nigeria.

\section{Waste Storage}

Household sanitary dustbins or disposable refuse bags for collection and storage of household wastes shall be promoted. The sanitary dustbins either galvanized or plastic of about $20 \mathrm{~kg}$ capacity shall be fitted with two handles and a well-fitting cover to prevent fly infestation and odour nuisance. The bins shall be kept out of reach of domestic animals, to prevent spillage of refuse. The galvanized dustbin shall be kept in a non-moist area to prevent corrosion. The dustbins shall be emptied into designated solid waste depot located within the area. Appropriate colour codes shall be adopted for segregation or sorting of domestic and hazardous wastes.

For commercial areas e.g. Market, etc., mammoth bins shall be placed at strategic locations to accommodate the large volume of solid waste generated at the market place.

For industrial premises, dinosaur bins of about $1500 \mathrm{~kg}$ should be placed at strategic locations within such premises to retain solid wastes generated.

\section{Efficient waste collection in local government level}

The Local Government shall:

- Conduct studies and classify all settlement according to their level of urbanization, size, function and economic base into urban, semiurban and rural.

- Review existing collection equipment, method, and frequencies, as well as the tradition and labour practices.

- Determine the most efficient system of waste collection for each settlement category and:

i. Set out the method of refuse pick,

ii. Determine manpower and equipment needs,

iii. Determine vehicle type and routing system

- Integrate as much as possible, the various waste collection methods adopted for the different levels of settlements. 
- Introduce standardized waste storage bins, but where this is not immediately possible; existing storage bins shall be made functional and safe.

- Implement collection methods that take into account differences in residential districts of a city as indicated below:

- Residential Area Collection method.

- Well planned, high income, low density areas

- House to house

- In case of communal depots, adequate numbers shall be provided within 200 to 250 meters walking distance to residences.

- Set up an efficient system for sanctioning and enforcement.

- Monitor, evaluate and re-plan at regular intervals.

\section{Collection Equipment}

In the choice of waste collection vehicles and equipment, emphasis shall be on optimizing vehicle and labour for improved productivity. The following guidelines are offered for vehicle choice:

i. A variety of non-motorised vehicles, which are human or animal powered are the most appropriate to be used as primary refuse collection vehicles in areas inaccessible to motor vehicles, such as in high density areas with poor road access; or when haul distance is short. Examples of such vehicles include:

a) Handcarts - with container capacity of about $200 \mathrm{~kg}$ have economic radius of operation of about $1 \mathrm{~km}$.

b) Pedal tricycles-with container capacity up to $500 \mathrm{~kg}$, have economic operation radius of about 2-3 km.

c) Animal drawn carts - have limited capacity of about 2 cubic meter, with an economic radius of operation of about $3 \mathrm{~km}$.

ii. In densely populated areas, heavy motorized vehicles often create problems. In such circumstances and particularly where haul distance is long, the collected intra settlement wastes can be transferred from a small vehicle to a large one at the periphery of settlements or at an appropriate location created as transfer station.

iii. The compactor truck is uneconomical and inappropriate in most areas because non- compaction vehicles can adequately collect our type of waste.

The choice of solid waste handling machine and equipment shall comply with the set guidelines of the Federal Government

The programme of equipment procurement shall be accompanied by maintenance agreement.

\section{Transfer Stations}

The need for transfer stations has been recognized particularly for some large metropolitan centers. Transfer stations shall be established where any of the following conditions subsist:

i. Where disposal sites cannot be located near the sources of solid waste generation.

ii. Where the responsibilities for waste management are separated and in the hands of different agencies.

iii. Where labour and transportation costs are high, particularly for haulage business.

Transfer station shall be built where public objection to its construction is limited and transport cost is optimized.

\section{Waste Transportation}

Intra-city and inter-city transportation of solid waste shall comply with the following guidelines:

- Choice of vehicles shall comply with set guidelines on equipment procurement.

- Transport vehicles shall be covered to prevent unhealthy spread and dispersal of waste.

- Transport itinerary shall be planned and properly routed in a manner that will not encumber intracity mobility.

\section{Management Options}

Four (4) management options are recommended:

i. By Local Government/Municipal Agencies;

ii. By Private Companies on contract with the LGA/Municipality;

iii. By Private Companies on contract with Home Owners.

iv. By public/private partnership

Direct operations of waste management by LGA/Municipal Agencies may be embarked upon where the private initiative is low. This practice is often bedeviled with frequent personnel turnover and the use of incompetent or untrained officials. Although money may be saved, it may be at the expense of satisfactory performance.

Contracting out waste collection to private contractors by the LGA/ Municipal Agency has its advantages. First, waste collection is conducted as a business venture without political considerations. Similarly, the burden of expenditure for equipment and capital outlay is placed on private companies while collection is effective. However, it may sometimes be counter- productive, as profit is the object of service. Also, contractual obligations are fixed and inflexible to changing conditions, as alterations in collection practices will require review in terms of contract. Furthermore, there are dual risks. One occurs in case of non-renewal 
of contract in spite of high capital outlay by the private contractor. The other is the risk to Government in case the private contractor fails.

Contract with individual house-owners is a frequent occurrence in sub-urban or rural areas where the LGA/Municipality does not usually render waste collection services. The practice has been found to be highly competitive and often uneconomic. There is usually price cutting by operators, which leads to low service standard. However, if properly organized and well monitored by the LGA, the service can be very effective in ridding the city of waste.

Public private partnership, which is the latest practice all over the world, shall be encouraged as this service will without doubt complement the efforts of the Government at getting rid of solid waste heaps in the city. Apart from the fact that the system will create more employment and alleviate poverty of the operators, the revenue base of the LGA will be significantly increased through the registration and licensing of such operators. However, the Government on its part shall promote and organize this sector through the creation of appropriate enabling environment.

\section{Private Sector Participation}

Private sector participation shall be hinged on the principle of fair play and transparency that is devoid of political undertones. The selection of private sector participants in Solid Waste Management shall be organized as follows:

- Franchised area shall be planned and mapped.

- Criteria for company qualification and selection shall be clearly stated.

- Indicators for franchised performance shall be specified.

- Terms of Reference and Conditions of Engagement of the private sector participant shall be well defined.

- Monitoring and evaluation procedures shall be outlined.

- Entire operations shall be backed by Legislation.

\section{Sanctions and Enforcement Mechanisms}

Mobile Sanitation Courts have become necessary to encourage public compliance with set rules and regulations, enforce standards and ensure positive attitudinal changes. In this regard, the following shall be put in place:

- Bye-laws on Solid Waste Management stipulating service standards and operations as well as citizen's obligations, shall be enacted.

- The Bye-laws shall be adequately disseminated to all communities.
- Local and mobile courts shall be established where they do not exist, to try offenders and impose sanctions.

- Sanctions shall be strictly enforced.

\section{Reward for best practices}

Each tier of Government shall identify best practices based on set criteria for exposition and reward.

Replication of best practices shall be encouraged.

\section{CONCLUSION}

In summary, there are four main ways that most city governments in developing countries can enhance waste reduction:

1. Inform citizens about source separation and recycling, and the needs of waste workers: extensive public education is needed to develop understanding of the need for further source separation to improve the potential for composting and to remove the stigma of association with waste materials.

2. Promote recycling industries and enterprises.

3. Divert organics. The greatest relief for the waste authority will come from reduction of organics, which implies, in the main, successful composting. Keeping organics pure for composting will require more thorough source separation than is done at present.

4. Advocate key areas for waste reduction at the manufacturing level (e.g., reduction of plastic packaging; coding of plastics to improve recycling).

\section{RECOMMENDATION}

- Promote waste minimization at household and community levels, through reduction at source, reuse, recycling and resource recovery.

- Evolve and promote appropriate technologies for recycling of waste components such as bottles, glass, metals, paper, plastic and organic matter.

- Foster the establishment of small-scale waste recycling plants at household and community levels, to source for and convert recyclable waste.

- Develop technical capacity of public and private sector agencies in Solid Waste Management.

- Conduct research to determine per capita waste generation and build a database on Solid Waste Management.

- Establish regulations, sanctions and enforcement mechanisms for Solid Waste Management from source of generation to the point of disposal. 
- Develop a Solid Waste Master Plan as a national blue print for effective Solid Waste Management.

- Evolve realistic and sustainable funding mechanisms.

- Create public awareness and sensitization on efficient municipal Solid Waste Management practices.

- Ensure effective monitoring and evaluation of municipal Solid Waste Management practices

- Set health criteria for manual sorting of wastes at household and community levels.

\section{REFERENCE}

Adegoke O.S. (1989). Waste Management within the Context of Sustainable Development. Proceedings of the Environment and Sustainable Development in Nigeria Workshop, 25 - 26 April, Abuja Nigeria, pp. $103-110$.
Agunwamba (1998). Solid waste management in Nigeria problems and issues. Environmental Management, 22(6): $849-856$.

Federal Military Government (1988). Federal Environmental Protection Agency Decree No. 58: A 911 - A 932.

FEPA (1998) (Federal Environmental Protection Agency). National Policy on the Environment. Nigeria: FEPA, P. 22.

FRN (Federal Republic of Nigeria) 1991. Official Gazette 78 (42): B15 - B37.

Njoku Jude (2006). Iddo: Where human waste is dumped with impunity. Vanguard, Monday, September 18, P. 42.

Okecha S.A. (2000). Pollution and Conservation of Nigeria Environment. $\mathrm{T}$ Afrique International Associates Owerri Nigeria.

Singh S.K. (1998). Solid waste management: An overview of environmental pollution. Environmental Control Journal, I (3): 50-56.

Uwaegbulam C. (2004). World is meeting goals of safe drinking water but falling behind on sanitation, says UN. The Guardian, Monday, August 30, P. 50. 